Revistade
Economila
Contemporâned

\title{
A EFICÁCIA DO CRÉDITO COMO CANAL DE TRANSMISSÃO DA POLÍTICA MONETÁRIA NO BRASIL: ESTRATÉGIA DE IDENTIFICAÇÃO DA OFERTA E DEMANDA DE CRÉDITO
}

\author{
Thamirys Figueredo Evangelista ${ }^{a}$ \\ Eliane Cristina de Araújo ${ }^{b}$

\begin{abstract}
${ }^{a}$ Mestre em Economia pela Universidade Estadual de Maringá (UEM).
'Professora associada do Departamento de Economia da UEM e pesquisadora do CNPq.
\end{abstract}

Artigo recebido em 22/12/2016 e aceito para publicação em 27/04/2018.

RESUMO: O principal objetivo deste trabalho foi investigar evidências empíricas a respeito da eficácia do crédito como canal de transmissão de política monetária no Brasil para o período de 2002 a 2012, no qual a proporção do crédito em relação ao PIB cresceu substancialmente. Para cumprir o propósito da pesquisa foram estimados diferentes modelos VAR e foram analisadas as funções impulso-resposta e a decomposição da variância dos erros. A estratégia de identificação da demanda e da oferta de crédito foi por meio de choques no volume real de crédito e na taxa de juros de mercado, respectivamente. Os resultados indicaram a existência do canal do crédito bancário. Desse modo, é aconselhável que as autoridades monetárias deem maior atenção aos efeitos da política monetária sobre o nível da taxa de juros de mercado, uma vez que o efeito da política monetária sobre esta potencializa a resposta da economia real.

PALAVRAS-CHAVE: mecanismos de transmissão de política monetária; canal do crédito bancário; identificação da oferta e da demanda do crédito bancário.

CLASSIFICAÇÃO JEL: E51; E52; E58; G21.

Correspondência para: Thamirys Figueredo Evangelista

Contato: thamirys.evangelista@gmail.com 


\section{THE EFFECTIVENESS OF CREDIT AS A TRANSMISSION CHANNEL OF THE MONETARY POLICY IN BRAZIL: THE IDENTIFICATION STRATEGY OF THE OFFER AND CREDIT DEMAND}

ABSTRACT: The main objective of this study was to determine the effectiveness of credit as a channel of monetary policy transmission in Brazil, based on empirical evidence for the period 2002-2012, when the ratio of credit to GDP grew substantially. With that purpose, we estimated different VAR models and analyzed the impulseresponse functions and the decomposition of the variance of errors. Credit demand and supply were determined by shocks in the actual volume of credit and market interest rates, respectively. The results indicated the existence of the credit channel. Thus, it is advisable that the monetary authorities give more attention to the effects of monetary policy at the level of market interest rates, since the effect of monetary policy on it enhances the response of the real economy.

KEYWORDS: monetary policy transmission mechanisms; channel bank credit; identification of the supply and demand of bank credit. 


\section{INTRODUÇÃO}

A discussão a respeito dos canais de transmissão de política monetária teve como marco o simpósio The Monetary Transmission Mechanism, realizado em 1995. Os artigos decorrentes desse evento ${ }^{1}$, publicados no Journal of Economic Perspectives no mesmo ano, apontaram que os principais canais de transmissão da política monetária são: o canal da taxa de juros ou canal da moeda, o canal da taxa de câmbio, o canal de preço de ativos (a teoria q de Tobin e o canal da riqueza) e o canal do crédito. Os três primeiros são os mecanismos mais tradicionais na literatura econômica, enquanto que o último apresenta uma abordagem não convencional de transmissão de política monetária.

Dentre os canais tradicionais, o canal da taxa de juros é o mais importante e, de acordo com Mishkin (1995), por mais de 50 anos esse foi o principal meio de transmissão de política monetária tratado nos estudos referentes ao tema, posto que é o mecanismo implícito nas análises keynesianas, sendo abordado no conhecido modelo IS-LM sistematizado por Hicks (1937). No entanto, a dificuldade do canal da taxa de juros e das demais teorias convencionais para explicar, de forma satisfatória, a ligação entre os efeitos que as alterações na taxa de juros têm sobre as variáveis reais fez com que o canal de crédito ganhasse relevância (BERNANKE e GERTLER, 1995). Bernanke e Gertler (1995) referem-se a essa lacuna nos modelos tradicionais como "caixa preta".

A abordagem do canal de crédito se subdivide na análise do canal de crédito amplo, também conhecido como canal do balanço patrimonial, e na análise do canal de empréstimos bancários. O presente trabalho irá se pautar no canal de empréstimos bancários, visto que esse canal vem ganhando importância na literatura econômica do Brasil devido ao aumento da razão crédito/Produto Interno Bruto (PIB) após a implantação do regime de metas de inflação.

De acordo com dados disponibilizados pelo Banco Central do Brasil (BCB), no período compreendido entre janeiro de 2002 e dezembro de 2012, o saldo das operações de crédito em relação ao PIB mais do que dobrou, ao passar de 25,7\% para 53,5\%, respectivamente - aumento de 27,8 pontos percentuais (p.p). Tal crescimento foi puxado pela modalidade de crédito livre, que aumentou sua participação no PIB em 16,8 p.p (de 16,9\% em janeiro de 2002 para 33,7\% em dezembro de 2012), enquanto que o crédito direcionado registrou crescimento de 10,9 p.p (de 8,9\% em janeiro de 2002 para 19,8\% em dezembro de 2012). Diversas medidas adotadas pelo Banco Central contribuíram para o aumento do segmento do crédito livre ao longo desse período. Dentre as medidas

1 Os artigos apresentados no simpósio The Monetary Transmission Mechanism foram os estudos realizados
por Bernanke e Gertler (1995), Meltzer (1995), Mishkin (1995), Obstfeld e Rogoff (1995) e Taylor (1995). 
que mais se destacaram foram a regulação do crédito consignado, o que impulsionou de forma considerável o setor de empréstimos pessoais (Lei no 10.820 , de 17 de dezembro de 2003), a aprovação da nova lei de falências (Lei no 11.101, de 9 de fevereiro de 2005) e os cartões de crédito ${ }^{2}$.

O número de pesquisas empíricas a respeito da operacionalidade do canal do crédito aumentou nas duas últimas décadas, no entanto as evidências ainda carecem de consenso, pois os resultados dos estudos são conflitantes. No centro da controvérsia está a dificuldade de isolar os movimentos da oferta de empréstimos daqueles causados pela demanda de empréstimos, pois, para que o canal do crédito esteja ativo, é necessário que a política monetária afete a oferta de crédito, caso contrário, se apenas a demanda for afetada, o mecanismo em funcionamento seria o canal da taxa de juros. A dificuldade de identificar corretamente a oferta de crédito reside no fato de que uma alteração na política monetária pode afetar o nível de empréstimos tanto pela demanda quanto pela oferta de crédito.

Sendo assim, esta pesquisa busca fornecer subsídios para o melhor entendimento a respeito dos mecanismos de transmissão da política monetária via canal de crédito bancário na economia brasileira após a implantação do regime de metas de inflação. A análise é realizada para o período de janeiro de 2002 a dezembro de $2012^{3}$, e a metodologia econométrica utilizada é o método de Vetores Autorregressivos (VAR). Ressalta-se que a modalidade de crédito utilizada é a de crédito livre, visto que, de acordo com Denardin e Balbinotto Neto (2014), essa modalidade de crédito está mais diretamente relacionada às reais condições de mercado e muito mais diretamente acometidas por problemas informacionais que a modalidade de crédito direcionado e,

2 Contudo, no período compreendido entre 2008 e 2011, a expansão do crédito livre sofreu um arrefecimento, reflexo dos efeitos da crise financeira internacional de 2008. Nesse período houve um aumento dos custos de captação dos bancos via Certificado de Depósitos Bancários (CDB), que foram repassados aos tomadores mediante elevação da taxa de juros nos segmentos de recursos livres. Em contrapartida, a retração do crédito livre no período foi compensada pelo aumento do volume do crédito direcionado, decorrente das políticas anticíclicas promovidas pelo Governo.

3 O período nomeado para a análise exclui os anos 1990 porque, de acordo com Carneiro, Salles e Wu (2006), até meados dessa década, a alta inflação no Brasil apresentou-se como obstáculo para a transmissão da política monetária via canal do crédito. A elevada variabilidade da taxa de inflação nesse período gerou uma grande instabilidade das taxas de juros reais, o que paralisou o mercado de crédito bancário. Ainda após a adoção do Plano Real, que reduziu a variância da inflação, a variabilidade das taxas reais de juros permaneceu elevada. De acordo com os autores, isso ocorreu devido ao uso da política monetária com a finalidade de impedir que sucessivos choques de oferta de moeda desorganizassem o esforço de construção de um ambiente de baixa inflação. O resultado dessa política foi uma proporção Crédito Privado/ PIB praticamente constante ao longo de todo o período do Plano Real. 
portanto, muito mais suscetíveis aos choques de política monetária ${ }^{4}$ O método para a identificação correta da oferta de crédito com a finalidade da identificação do canal é baseado no método proposto por Walsh e Wilcox (1995), que está descrito na seção 3 deste artigo. A principal contribuição da investigação está na análise desagregada para pessoa física e jurídica, realizada na seção 6.2, visto que a assimetria de informação, fator que afeta a oferta de crédito, afeta a ambos de forma diferenciada; logo acredita-se ser uma questão importante para a identificação do canal do crédito.

Em suma, este artigo conta com cinco seções, além desta introdução e da conclusão. Na próxima seção é descrita uma revisão de literatura teórica a respeito do canal do crédito. Na terceira seção apresenta-se o desafio da identificação da oferta e da demanda de crédito. Na seção quatro descrevem-se os dados e os modelos a serem estimados. Na quinta seção faz-se uma análise dos dados. Por fim, na sexta seção apresenta-se a estratégia utilizada para a identificação da oferta de crédito e os resultados desse método.

\section{REVISÃO DA LITERATURA}

O canal do crédito, em oposição aos canais tradicionais, principalmente ao canal da taxa de juros, estabelece que os mercados financeiros não consideram informação perfeita, pois existem imperfeições significativas nesses mercados que acabam por interferir na transmissão da política monetária e potencializam os efeitos desta na economia. Dada a incorporação dessas imperfeições na análise dos mecanismos de transmissão monetária, a visão do crédito apresenta resultados consistentes com a realidade, o que difere dos modelos tradicionais. Estes últimos apresentam resultados inconsistentes e viesados por não considerarem a existência de informação incompleta (BERNANKE e GERTLER, 1995). Em adição a esse argumento, Pacheco (2006) afirma que o canal do crédito, ao levar em consideração a existência de imperfeição de mercado, constitui-se em um mecanismo de transmissão mais completo se comparado com os tradicionais.

Com base na visão do crédito, a política monetária não afeta apenas a taxa de juros, mas também o Prêmio de Financiamento Externo (spread), o qual contribui para

4 O crédito livre é destinado, basicamente, ao consumo das famílias e ao financiamento do capital de giro das empresas, enquanto que o crédito direcionado tem as condições de oferta definidas pelo governo e contemplam principalmente os setores da indústria e da infraestrutura, no caso do crédito concedido pelo Banco Nacional de Desenvolvimento Econômico e Social (BNDES), e os setores habitacional e rural. 
explicar melhor a interação entre alterações das taxas de juros e variáveis reais da economia. Esse prêmio consiste na diferença de custos dos recursos captados externamente (emissão de títulos) e os custos dos recursos gerados internamente (retenção de lucros). A sua magnitude reflete as imperfeições do mercado que surgem da relação existente entre a expectativa de retorno dos emprestadores e os custos de capital com que se deparam os tomadores de empréstimo ${ }^{5}$.

Nesse sentido, uma mudança na política monetária que aumenta ou diminui a taxa de juros de open-market tende a alterar o prêmio de financiamento externo para a mesma direção. Assim, o impacto direto da taxa de juros sobre o custo dos empréstimos e, consequentemente, sobre os gastos reais e atividade real, é potencializado por mudanças no prêmio de financiamento externo (BERNANKE e GERTLER, 1995). Embora o tradicional canal da taxa de juros para a transmissão da política monetária ainda permaneça intacto, essa capacidade do canal do crédito de aumentar o impacto da política monetária sobre a economia tem lhe concedido maior credibilidade ao longo das últimas duas décadas (PEEK e ROSENGREEN, 2013).

Para explicar como as ações tomadas pelo Banco Central alteram o prêmio de financiamento externo e, por consequência, as condições em que o crédito é negociado e ofertado e seus efeitos na economia real, a análise do canal do crédito é subdividida em dois canais: o canal amplo do crédito (broad credit channel) ou canal de balanço patrimonial (balance sheet channel); e o canal do empréstimo bancário (bank lending channel).

Segundo Souza-Sobrinho (2003, p. 12), o primeiro "é uma explicação mais geral do canal do crédito, pois supõe que todas as fontes de financiamento externas (incluindo o empréstimo bancário) são substitutos imperfeitos para os fundos internos da firma (geração de caixa e lucros retidos)". O segundo, ainda de acordo com Souza-Sobrinho (2003, p. 12), "é um caso particular do canal amplo do crédito, pois enfatiza as implicações de apenas uma fonte de financiamento externo (a oferta de crédito bancário) para a transmissão de política monetária”. Bernanke e Gertler (1995) argumentam que a existência

5 As mudanças no prêmio de financiamento externo são fortemente relacionadas à existência de imperfeições no mercado de crédito - a principal suposição do canal de crédito. Carneiro, Salles e Wu (2006) afirmam que, em um mercado perfeito de crédito, a decisão de endividamento depende apenas dos retornos esperados dos investimentos. Assim, investimentos produtivos seriam sempre financiados, e os preços dos ativos refletiriam apenas o que ocorre no lado real da economia. No entanto, existe assimetria de informação (assimetric information) no mercado de crédito, que impede que ele funcione de forma perfeita e origina problemas de seleção adversa (adverse selection) e risco moral (moral hazard). A existência dos problemas de seleção adversa e risco moral tem como consequência o racionamento de crédito. Além desses problemas, existem também os efeitos lock-in, que, além de provocarem restrição de oferta de crédito, também aumentam o custo do crédito para bons pagadores. Para mais detalhes ver Arkelof (1970), Mishkin (1995) e Sharpe (1990). 
do canal de balanço patrimonial está relativamente bem estabelecida entre os pesquisadores, já o canal do empréstimo bancário é mais controverso.

O objetivo desse trabalho é contribuir para a literatura empírica acerca do canal de empréstimos bancários, logo a revisão de literatura a partir deste ponto irá se aprofundar nessa abordagem específica do canal do crédito.

\subsection{O CANAL DO EMPRÉSTIMO BANCÁRIO (BANK LENDING CHANNEL)}

O canal do crédito bancário incorpora ao modelo padrão IS-LM à curva do crédito, pois considera três ativos (moeda, títulos e empréstimos). A política monetária, além de afetar os balanços dos mutuários, também impacta o prêmio de financiamento externo ao deslocar a oferta de crédito, o que se traduz no canal de empréstimos bancários (BERNANKE e GERTLER, 1995).

As pesquisas acerca do canal dos empréstimos bancários atribuem um papel especial aos bancos. Essas instituições desempenham, por excelência, o papel de intermediárias entre oferta e demanda por crédito no sistema financeiro, operando na captação de poupança das famílias, por um lado, e provendo financiamento para o investimento privado, por outro. Em virtude da intensidade com que monitoram os projetos e a restrita e detalhada cobertura que fazem nos contratos de empréstimos, os bancos se tornam as instituições mais aptas para resolverem problemas de assimetria de informações e, assim, avaliarem a concessão do crédito (BERNANKE e GERTLER, 1995; BERNANKE e BLINDER, 1988).

As pequenas e médias empresas são grandes demandantes de empréstimos bancários, no entanto, em comparação às empresas de grande porte, são mais suscetíveis às imperfeições nos mercados de crédito e mais sensíveis a modificações na conjuntura macroeconômica, a contrações no produto e a choques de política monetária em razão das suas dificuldades de obtenção de recursos fora do mercado bancário, sendo os empréstimos bancários a única fonte de linha de crédito. Em contrapartida, grandes firmas são menos dependentes de crédito bancário por terem capacidade de se financiarem no mercado financeiro para obter recursos externos, sem precisar recorrer aos bancos (PEEK e ROSENGREN, 2013).

Para Kashiap e Stein (1993), Bernanke e Blinder (1988), Meltzer (1995) e Walsh (1988), três condições devem ser satisfeitas para a existência do canal de empréstimos bancários:

i) Assim como ocorre no ponto de vista da taxa de juros, a moeda não deve ser neutra no curto prazo, isto é, os preços não devem se ajustar totalmente e instantaneamente a uma mudança na oferta de moeda. Caso contrário, uma mu- 
dança nas reservas nominais pode ser acompanhada de uma variação proporcional no nível geral de preços, implicando na não alteração dos balanços das empresas, das famílias e dos bancos em termos reais. Por consequência, a política monetária não apresentaria um impacto no lado real da economia, isto é, na atividade produtiva;

ii) A segunda condição é de que, pressupondo que a oferta de empréstimos bancários tem uma dependência significativa dos depósitos bancários, as operações de mercado aberto realizadas pelo Banco Central devem ter a capacidade de alterar o nível de depósitos bancários (por meio de depósitos compulsórios, por exemplo), o que impactaria o passivo do balanço patrimonial e, indiretamente, a composição de portfólio dos bancos. Por conseguinte, a política monetária afetaria o volume de empréstimos concedido pelos bancos;

iii) Para que o canal seja relevante economicamente, isto é, tenha efeitos no lado real da economia, empréstimos bancários e títulos não devem ser substitutos perfeitos como uma fonte de crédito para algumas firmas, desse modo, o empréstimo bancário torna-se a única forma de financiamento dessas empresas, além de seus próprios recursos.

Nessa visão, dada a inclusão dos empréstimos como ativo, a economia opera com duas taxas de juros (juros sobre os títulos e juros sobre empréstimos), o que influencia diretamente nas decisões dos agentes e dá aos bancos um novo papel: além de ser um criador de moeda o banco também passa a ter o papel de emprestador, o que tem impacto no lado real da economia. Ao analisar o impacto na atividade econômica de uma política monetária a partir da visão do crédito, uma ação do Banco Central que restrinja o crédito causaria uma queda do nível de crescimento muito maior do que se analisasse pela visão da moeda, porque o efeito da política monetária está incluído na IS, o que não ocorre para o canal da taxa de juros (BERNANKE e BLINDER, 1988) ${ }^{6}$.

A Figura 1 apresenta os movimentos gerados por uma política monetária restritiva sobre as curvas IS, LM e "commodities and credit" (CC) e os efeitos sobre o produto. A curva CC representa uma curva IS modificada pela incorporação das reservas bancárias. Essa curva apresenta a mesma forma da IS, isto é, é negativamente inclinada, no entanto, ao contrário da curva IS, a curva CC reage a choques monetários que modificam as reservas e que afetam as funções do mercado de crédito. No caso da visão do crédito, uma redução das reservas bancárias decorrentes de uma política monetária restritiva provoca um deslocamento da curva LM para a esquerda, para LM', e, como o volume de crédito

6 Para uma formalização do canal do crédito, ver Bernanke e Blinder (1988). 
se reduz, a curva CC também se desloca para a esquerda, para CC. A contração da oferta de crédito provoca uma piora nas condições de investimento para as firmas e, como consequência, o produto apresenta uma queda significativa, passando de $y^{\star}$ para $y^{C C}$. No caso do visão tradicional, a IS não sofre efeitos de uma política monetária restritiva, apenas a curva LM se deslocaria e, consequentemente, o efeito da renda seria menor, passando de $y^{*}$ para $y^{I S}$ e a taxa de juros se elevaria de $i^{*}$ para $i^{I S}$.

Figura 1 - 0 canal do crédito da política monetária

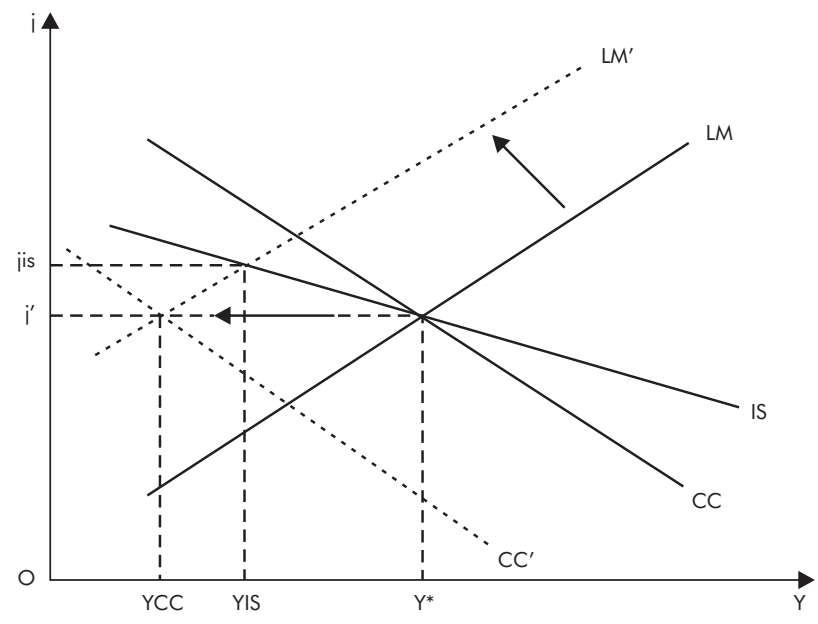

Fonte: Freitas e Rochet (1997) apud Denardin (2007)

Por meio desse gráfico verifica-se que os efeitos da política monetária no lado real da economia não são completamente explicados pelas alterações da taxa de juros no mercado aberto, mas são explicados também pelas alterações de oferta de crédito dos bancos. O efeito real de um aumento da taxa de juros foi melhor captado e amplificado pelo canal do crédito em comparação com o canal da taxa de juros, isso porque os investimentos caem não somente devido a um aumento no custo de capitais, que forçam grande parte das firmas (inclusive as de grande porte) a cortarem gastos com investimento, mas também devido a uma contração da oferta de empréstimos, que afeta principalmente firmas de pequeno e médio porte, o que acelera o declínio da atividade econômica.

Assim, conclui-se que a existência do canal de empréstimos bancários potencializa os efeitos de uma política monetária em comparação com o caso do canal da taxa de juros, o que torna o canal dos empréstimos bancários relevante para o crescimento da economia. Isso ocorre porque o Banco Central, além de ser a instituição responsável por criar moeda, também influencia o nível de empréstimos dos bancos. Uma política monetária expansionista que aumente as reservas bancárias amplia o volume de em- 
préstimos, o que privilegia as empresas de pequeno e médio porte, pois estas dependem quase $100 \%$ dos empréstimos bancários por não terem acesso ao mercado de capitais, isto é, não emitem ações para financiar sua produção.

Esse canal pode ser sintetizado da seguinte forma: uma política monetária restritiva $(\mathrm{M} \downarrow)$ capaz de provocar uma redução de depósitos bancários aumentaria os problemas de seleção adversa e risco moral (SA $\uparrow \& \mathrm{RM} \uparrow$ ), o que aprofundaria o grau de assimetria de informação desse mercado e consequentemente reduziria os empréstimos bancários (Eb $\downarrow$ ). Esse processo gera um aumento do prêmio de financiamento externo, que comprometeria os gastos em consumo (C $\downarrow$ ) e investimentos (I $\downarrow$ ), causando a redução da demanda agregada e desencadeando a queda do produto da economia $(\downarrow)$. Esquematicamente, tem-se:

$$
\mathrm{M} \downarrow \rightarrow \mathrm{i} \uparrow \rightarrow \mathrm{SA} \uparrow \& \mathrm{RM} \uparrow \rightarrow \mathrm{Eb} \downarrow \rightarrow \mathrm{C} \downarrow \mathrm{e} \mathrm{I} \downarrow \rightarrow \mathrm{Y} \downarrow
$$

A análise do canal do crédito, segundo Bernanke e Gertler (1995), também pode ser expandida sobre os gastos dos consumidores. De acordo com essa visão, existe outro mecanismo de transmissão para a política monetária que emerge por meio da interação entre a moeda e os preços das ações. Quando é esperada queda nos preços das ações (Pa $\downarrow$ ), o valor dos ativos financeiros tende a cair (VAF $\downarrow$ ), o que leva a uma maior probabilidade de ocorrência de uma crise financeira (CF个). Assim, diante de

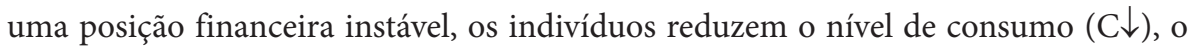
que leva à queda do produto da economia (Y $\downarrow$ ) (BERNANKE e GERTLER, 1995). Esquematicamente, tem-se:

$$
\mathrm{M} \downarrow \rightarrow \mathrm{i} \uparrow \rightarrow \mathrm{Pa} \downarrow \rightarrow \mathrm{VAF} \downarrow \rightarrow \mathrm{Eb} \downarrow \rightarrow \mathrm{CF} \uparrow \rightarrow \mathrm{C} \downarrow \rightarrow \mathrm{Y} \downarrow
$$

De acordo com Fuinhas (2002), a política monetária restritiva melhora a qualidade do crédito bancário pois os bancos reduzem o volume de crédito para os tomadores de maior risco. Para isso, adotam o meio de seleção adversa e garantem o crédito para aqueles que oferecem uma garantia melhor. Em contrapartida, isso pode desencadear uma recessão econômica, que, por sua vez, desencadeia uma maior restrição ao crédito, acentuando cada vez mais a recessão.

\section{DESAFIO DE IDENTIFICAÇÃO DA OFERTA E DA DEMANDA DE CRÉDITO}

Embora a visão do canal do crédito apresente uma abordagem simples para explicar os efeitos dos juros sobre o custo de captação das firmas, esse mecanismo não fornece 
uma maneira simples para compatibilizar a modelagem teórica com evidências empíricas minimamente convincentes (CARNEIRO, SALLES e WU, 2005). Existem vários desafios que os pesquisadores que procuram avaliar a operacionalidade do canal do crédito enfrentam ${ }^{7}$, dentre os quais destaca-se a identificação dos choques de oferta de crédito. Segundo Peek e Rosengren (2013), tal dificuldade ocorre porque uma queda no nível dos empréstimos após um aperto da política monetária pode refletir um declínio na demanda de empréstimos em vez de uma retração na oferta dos mesmos.

Mais especificamente, no caso de um choque monetário restritivo, ocorre uma redução dos depósitos bancários, e, daí, seguem-se duas possibilidades. A primeira é que os bancos podem conseguir recursos no mercado e manter as operações de empréstimos no mesmo nível que antes do choque, no entanto, a consequente retração da atividade econômica pode implicar em queda da demanda por empréstimos. A segunda ocorre quando os bancos não conseguem recursos alternativos e têm que reduzir a oferta de crédito. Dessa forma, a redução dos empréstimos pode originar choques em sua demanda e/ou em sua oferta (BEZERRA, SILVA e LIMA, 2013).

Para contornar esse problema inerente à análise da oferta e da demanda de crédito, muitos estudos utilizam dados desagregados por firmas bancárias ${ }^{8}$. A hipótese implícita nesses estudos é a de que as características dos balancetes dos bancos (tamanho, liquidez, capitalização, dentre outras) determinam o nível de crédito ofertado na economia, dado que essas características expressam a capacidade de realizar empréstimos e são independentes dos choques na demanda por estes. Entretanto, esse tipo de análise não permite estimar o efeito macroeconômico do canal de transmissão da política monetária via crédito.

Já as pesquisas que utilizam dados agregados apresentam maior dificuldade em identificar a oferta de crédito $^{9}$, uma vez que a grande maioria utiliza um instrumento diretamente ligado à política monetária, a taxa de juros da política monetária (no caso do Brasil, a Selic), para a identificação da oferta de crédito, deixando-os mais suscetíveis às críticas em relação à endogeneidade que acomete esse tipo de análise. Em contrapartida, essa análise possibilita o efeito final do canal de transmissão do crédito sobre a demanda agregada.

7 Ver Peek e Rosengren (2013).

8 Algumas dessas pesquisas aplicadas para o Brasil foram as realizados por Araújo (2012), Takeda, Rocha e Nakane (2005) e Graminho (2002).

9 Algumas dessas pesquisas aplicadas para o Brasil foram as realizados por Abrita et al. (2014), Fonseca (2008) e Souza Sobrinho (2003). 
Apesar dessa dificuldade apontada sobre os estudos agregados, Walsh e Wilcox (1995), em um estudo realizado para os Estados Unidos e utilizando o método VAR com base na ordenação de Cholesky, demonstraram que é possível contornar o problema de identificação da oferta de empréstimos bancários utilizando dados agregados. Esses autores se valem de choques na taxa de juros de mercado como proxy para identificar a oferta de empréstimos, enquanto a demanda é identificada por choques no volume de empréstimos. Vale dizer que a taxa de juros de mercado utilizada nesse estudo não se refere à taxa básica de juros da economia regulada pelo Banco Central local, mas sim a uma taxa de juros mais representativa daquela vigente no mercado de crédito.

De acordo com a teoria do canal do crédito, em uma situação de aperto monetário, caso os bancos não consigam recursos alternativos para manter os níveis de crédito no mesmo nível que antes do choque, eles terão que reduzir a oferta de crédito, como já discutido. Dessa forma, um aumento da Selic irá aumentar a taxa de juros de mercado, pois os bancos irão querer compensar a perda de rentabilidade causada pela redução da diferença entre as duas taxas. Assim, a elevação da taxa de juros de mercado irá refletir um choque negativo de oferta de crédito. Um choque positivo no volume de crédito, por sua vez, irá captar um aumento na demanda por crédito, visto que os agentes irão demandar mais recursos em momentos de crescimento da economia.

A justificativa para utilizar a taxa de juros de mercado para identificar a oferta de crédito deve-se ao fato de que essa variável não está ligada tão diretamente à política monetária quanto a taxa de juros da política monetária. Desse modo, o modelo não recairia no problema de endogeneidade que os pesquisadores do canal do crédito enfrentam, sendo essa uma das principais contribuições do trabalho de Walsh e Wilcox (1995) para essa literatura.

Dito isso, utiliza-se nesta pesquisa o método proposto por Walsh e Wilcox (1995) para verificar a operacionalidade do canal do crédito da política monetária para o período de 2002 a 2012. No Brasil, o argumento de que a taxa de juros de mercado reflete a oferta de crédito é reforçado quando se observa a influência da inflação no mercado de crédito no País. No período de alta inflação, entre o início dos anos 1980 até meados da década de 1990, o volume de crédito concedido era baixo, pois as taxas de juros do mercado eram altas para compensar a perda de receita do emprestador no período. Já nos anos 2000, a estabilidade dos preços alcançada por meio do Plano Real permitiu ao setor bancário reduzir as taxas de juros, proporcionando uma maior oferta de crédito em relação à década anterior.

Além de procurar identificar a oferta e a demanda de crédito, amplia-se a análise ao desagregá-la para o mercado de crédito da pessoa física e da pessoa jurídica a fim de verificar a importância relativa de ambas sobre a economia. Nesse caso, o esperado é que o mercado mais vulnerável aos problemas de assimetria de informação sofra mais com um choque de oferta de crédito. 


\section{APRESENTAÇÃO DOS DADOS E METODOLOGIA}

A base de dados utilizada neste estudo é do tipo séries temporais com periodicidade mensal e que compreendem os anos de 2002 a 2012, contemplando um total de 132 observações. O período escolhido inicia-se em 2002 porque esse foi o ano em que o volume de crédito como proporção do PIB iniciou uma tendência de crescimento sustentada, e encerra-se em 2012 porque algumas das variáveis utilizadas estão disponíveis até esse período. Abaixo estão descritas as variáveis utilizadas:

- LOGIND - Logaritmo da série produção industrial - indústria geral - quantum - índice (média $2002=100$ ). Fonte: IPEADATA/ IBGE-PIM-PF;

- INFLAÇÃO - Inflação - IGP-DI (em \% a.m.). Fonte: IPEADATA/ FGV;

- SELIC - 4390 - Taxa de juros - Selic acumulada no mês (em \% a.m). Observação: variável equivalente à Federal Funds Rate usada por Walsh e Wilcox (1995). Fonte: BCB- SGS;

- JUROS - 3951 - Taxa média mensal (pré-fixada) das operações de crédito com recursos livres referenciais para taxa de juros (Total geral em \% a.a.). Observação: variável equivalente à Prime Rate usada por Walsh e Wilcox (1995). Fonte: BCB- SGS;

- JUROS_PF - 3953 - Taxa média mensal (pré-fixada) das operações de crédito com recursos livres referenciais para taxa de juros (Total pessoa física, em \% a.a.). Fonte: BCB- SGS;

- JUROS_PJ - 3952 - Taxa média mensal (pré-fixada) das operações de crédito com recursos livres referenciais para taxa de juros (Total pessoa jurídica, em \% a.a.). Fonte: BCB- SGS;

- LOGCRÉDITO - Logaritmo da série 3958 - Saldo consolidado no mês das operações de crédito com recursos livres referenciais para taxa de juros (Total geral, em mil u.m.c.). Fonte: BCB- SGS;

- LOGCRÉDITO_PF - Logaritmo da série 3960 - Saldo consolidado no mês das operações de crédito com recursos livres referenciais para taxa de juros (Total pessoa física, em mil u.m.c.). Fonte: BCB- SGS;

- LOGCRÉDITO_PJ - Logaritmo da série 3959 - Saldo consolidado no mês das operações de crédito com recursos livres referenciais para taxa de juros (Total pessoa jurídica, em mil u.m.c.). Fonte: BCB- SGS.

No que diz respeito ao tratamento das séries, destaca-se que:

i) A série de crédito foi tomada em termos reais, seu valor foi corrigido para valores de dezembro de 2012. O deflator utilizado foi o Índice Nacional de Preços ao Consumidor-Amplo (IPCA); 
ii) As séries de produção, inflação ${ }^{10}$ e crédito foram ajustadas sazonalmente por meio do método multiplicativo X-12;

iii) As variáveis do produto e do crédito foram transformadas em logaritmos e são interpretadas como a taxa de crescimento acumulada relativa à base. As séries da inflação, da Selic e das taxas de juros são expressas em percentagem, portanto são interpretadas como variações percentuais relativas à base.

Serão estimados três modelos VARs com base na ordenação de Cholesky. A seguir apresentam-se as variáveis e a ordenação destas para cada modelo estimado:

- $\quad$ LOGIND, INFLAÇÃO, SELIC, JUROS e CRÉDITO (Modelo 1);

- LOGIND, INFLACAO, SELIC, JUROS_PF, LOGCRÉDITO_PF (Modelo 2);

- LOGIND, INFLACAO, SELIC, JUROS_PJ, LOGCRÉDITO_PJ (Modelo 3).

A ordem de inclusão das variáveis nos modelos foi a mesma proposta por Walsh e Wilcox $(1995)^{11}$. O modelo 1 foi estimado com o intuito de verificar os efeitos de um choque na oferta (JUROS) e na demanda (CRÉDITO) do crédito agregado. Os modelos 2 e 3 foram realizados para averiguar os efeitos de um choque na oferta de crédito da pessoa física (JUROS_PF) e da pessoa jurídica (JUROS_PJ), respectivamente.

No que diz respeito à ordenação de Cholesky, refere-se a uma estrutura ordenada de resíduos de forma triangular, o que implica uma estrutura exatamente identificada do modelo. Supõe-se uma estrutura de causalidade contemporânea em relação à ordenação das variáveis do sistema, de modo que a primeira variável no ordenamento não é afetada por choques nas demais variáveis, mas choques na primeira variável afetam contemporaneamente as demais variáveis do sistema. A segunda variável é afetada somente pela primeira variável do sistema, mas os choques sobre a segunda variável afetam contemporaneamente as variáveis seguintes, e assim sucessivamente. Em ter-

10 Para fazer o ajuste sazonal na variável inflação foi necessário somar 1 a todas as observações.

11 A ordenação das variáveis adotada por Walsh e Wilcox (1995) teve como base o estudo de Friedman e Kuttner (1993). Os últimos utilizaram argumentos teóricos para a ordenação destas. Uma vez que o intuito desta pesquisa é aplicar o modelo proposto por Walsh e Wilcox (1995), utilizou-se a mesma ordenação das variáveis utilizada por esses autores. Ademais, com base em Cavalcanti (2010), preferiu não se utilizar o teste de Causalidade de Granger para essa finalidade. Esse autor faz um alerta a respeito de um erro comum na literatura macroeconômica aplicada ao Brasil associado à identificação de modelos VAR com base nos resultados desse teste. Ele afirma que "o conceito de causalidade de Granger não guarda necessariamente nenhuma relação com a ocorrência (ou não) de efeitos contemporâneos de uma variável sobre outra”. Por consequência, um modelo VAR que apresenta uma ordenação das variáveis com base nos testes de Causalidade de Granger expressa uma ordenação causal contemporânea equivocada. O objetivo do autor nesse trabalho foi evitar uma ulterior propagação desse erro, que já vinha sendo cometido em diversos trabalhos realizados no Brasil. Para maiores detalhes ver Cavalcanti (2010). 
mos do modelo aqui estimado, pressupõe-se que a produção industrial é a variável mais exógena do sistema, não sofrendo influências contemporâneas de nenhuma das outras variáveis; já a variável inflação sofre efeitos contemporâneas apenas da produção industrial; a Selic é afetada contemporaneamente pela produção industrial e a inflação; os juros são afetados contemporaneamente pela produção industrial, a inflação e a Selic; e o crédito, por sua vez, é a variável mais endógena do sistema, sofrendo influência contemporânea de todas as outras variáveis.

Os coeficientes dos diferentes modelos VAR estimados não foram diretamente interpretados, visto que a existência de multicolinearidade os torna, na maioria das vezes, não significativos estatisticamente. Assim, no presente estudo, as análises foram feitas a partir das funções impulso-resposta e da decomposição da variância dos erros. As funções impulso-resposta permitem captar o efeito dinâmico de um choque exógeno sobre as variáveis do modelo em um determinado horizonte de tempo. Além disso, por meio desse método é possível averiguar o tempo em que os efeitos de um choque sobre determinada variável são dissipados e a intensidade das respostas em consequência dos choques. No que concerne à decomposição da variância, esta informa o quanto a variância do erro de previsão de uma série é explicada pela própria série ou por outras séries.

\section{ANÁLISE DOS DADOS}

A primeira etapa da análise de séries temporais é verificar se as séries seguem um processo estocástico estacionário ao longo do tempo. Para verificar a existência ou não da estacionariedade na série de tempo utiliza-se, nesta pesquisa, o teste de Dickey-Fuller Aumentado (ADF) e Phillips-Perron (PP). A hipótese nula desses testes é a de que a série testada possui raiz unitária, isto é, é não estacionária. Além de indicarem a existência ou não da raiz unitária, também permitem identificar a ordem de integração da variável em questão. Um resumo dos resultados de ambos os testes está apresentado na Tabela 1.

Tabela 1 - Resumo dos testes de raiz unitária aos níveis de significância de $1 \%, 5 \%$ e $10 \%$

\begin{tabular}{lcc}
\hline & ADF & PP \\
\hline LOGIND & $\mathrm{I}(1)$ & $\mathrm{I}(1)$ \\
INFLAÇÃO & $\mathrm{I}(0)$ & $\mathrm{I}(0)$ \\
SELIC & $\mathrm{I}(0)$ & $\mathrm{I}(0)$ \\
JUROS & $\mathrm{I}(0)$ & $\mathrm{I}(1)$ \\
LOGCREDITO & $\mathrm{I}(0)$ & $\mathrm{I}(0)$ \\
JUROS_PF & $\mathrm{I}(1)$ & $\mathrm{I}(1)$ \\
JUROS_PJ & $\mathrm{I}(1)$ & $\mathrm{I}(1)$ \\
LOGCREDITO_PF & $\mathrm{I}(0)$ & $\mathrm{I}(1)$ \\
LOGCREDITO_PJ & $\mathrm{I}(2)$ & $\mathrm{I}(1)$ \\
\hline
\end{tabular}

Fonte: Elaboração própria a partir da saída do software Eviews 8.0. 
Uma vez que diversas variáveis foram indicadas como não estacionárias pelos testes de raiz unitária, o próximo passo seria realizar testes de cointegração dos sistemas a serem estimados. Contudo, com base em Sims, Stock e Watson (1990), optou-se por não os realizar. Segundo esses autores, a finalidade da análise por meio de modelos autorregressivos é determinar as relações existentes entre as variáveis e não os parâmetros estimados, portanto não é relevante preocupar-se com a estrutura de cointegração que se estabelece entre as variáveis.

Logo, uma estimação de um VAR com todas as variáveis em nível mostra-se consistente. Destarte, para o propósito desta análise, que é identificar como diferentes variáveis reagem a um choque na oferta e demanda de crédito e a um choque na política monetária, um modelo assim especificado cumpre os propósitos deste estudo. Ademais, diversos trabalhos adotam essa suposição, como os de Bernanke e Gertler (1995), Dias Júnior e Denardin (2010) e Fonseca (2008).

Vale dizer que, após a estimação dos modelos VAR, foram realizados os testes usuais de diagnósticos dos resíduos (autocorrelação, heterocedasticidade e normalidade) com o propósito de confirmar a confiabilidade dos resultados.

\section{APRESENTAÇÃO DOS RESULTADOS}

\subsection{ESTRATÉGIA DE IDENTIFICAÇÃO DA OFERTA E DEMANDA DE CRÉDITO}

Com vistas a verificar a operacionalidade do canal do crédito para a economia brasileira, esta seção vale-se das funções impulso-resposta com o intuito de investigar os efeitos que inovações na demanda e na oferta de crédito têm sobre a economia para um horizonte de 48 meses (quatro anos). Escolheu-se esse longo período para facilitar a comparação dos momentos em que os choques se dissipam. Seguindo Walsh e Wilcox (1995), para a identificação desses eventos foram utilizadas inovações no volume de crédito (CRÉDITO) e na taxa de juro de mercado (JUROS), respectivamente. A hipótese sugerida pelos autores é a de que choques na demanda de empréstimos têm pouco, se é que algum, efeito sobre o volume real de crédito e sobre o produto, enquanto choques na oferta de crédito impactam de forma mais intensa o produto do que choques na demanda, como sugerido pela teoria do canal do crédito descrita na seção dois.

Para que o modelo VAR que inclui tanto a variável utilizada para determinar a oferta de crédito (taxa de juros de mercado) quanto a variável empregada para determinar a demanda de crédito (volume de crédito) seja considerado robusto, é necessário que essas variáveis não sejam determinadas conjuntamente, caso contrário a ordenação de Cholesky não identificaria separadamente as perturbações de oferta e demanda. Para verificar 
essa possibilidade estimou-se um VAR estrutural, no qual a taxa de juros de mercado e o montante de empréstimos foram assumidos como sendo simultaneamente determinados, com ambos respondendo a choques de oferta e demanda.

Esses choques foram identificados por meio de restrições a priori sobre as relações contemporâneas. Foi mantida a estrutura recursiva utilizada no VAR padrão, e, para identificar a equação de demanda, excluiu-se das relações contemporâneas a variável Selic, e, para a identificação da oferta, excluíram-se o produto e a inflação.

Na Tabela 2 verificam-se os coeficientes de correlação obtidos entre as estimativas obtidas no VAR estimado por meio da ordenação de Cholesky e as obtidas no VAR estrutural (SVAR). Observa-se que as respostas obtidas por meio de um choque na taxa de juros de mercado por intermédio do SVAR foram altamente correlacionadas com as respostas de um choque na taxa de juros de mercado via ordenação de Cholesky. Da mesma forma, os resultados de um choque nos empréstimos no SVAR foram altamente correlacionados com os resultados de um choque na quantidade de empréstimos obtidos via ordenação de Cholesky.

Tabela 2 - Coeficientes de correlação entre choques na demanda e na oferta de crédito do modelo VAR padrão com choques na demanda e na oferta de crédito do modelo VAR estrutural

\begin{tabular}{lcc}
\hline & Choque no volume real de crédito - demanda de crédito \\
\hline & crédito_SVAR & crédito_VAR \\
crédito_SVAR & 1 & 0.99999999998 \\
crédito_VAR & 0.99999999998 & 1 \\
\hline \multicolumn{2}{c}{ Choques na taxa de juros de mercado - oferta de crédito } \\
\hline juros_SVAR & juros_SVAR & juros_VAR \\
juros_VAR & 1 & 0.99999999998 \\
\hline
\end{tabular}

Fonte: Elaboração própria a partir da saída do software Eviews 8.0.

Esses resultados sugerem que a ordenação de Cholesky é capaz de identificar separadamente as perturbações de oferta e demanda tão eficazmente quanto o SVAR o faz. Assim, as próximas estimações foram obtidas via ordenação de Cholesky.

A Figura 2 apresenta as funções de resposta a impulso do modelo 1. As respostas do choque no volume de empréstimos estão representadas no lado esquerdo e as respostas do choque na taxa de juros de mercado estão representadas no lado direito. 


\section{Figura 2 - Funções de resposta a impulso no volume de crédito e na taxa média de juros de mercado}

Mod. 1 - Choque no crédito

Response of LOGIND to Cholesky

One S.D. LOGCREDITO Innovation

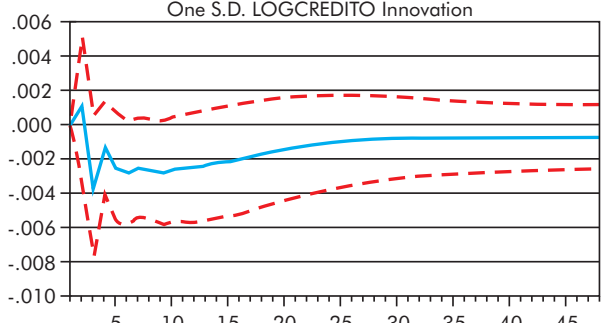

$\begin{array}{lllllllll}5 & 10 & 15 & 20 & 25 & 30 & 35 & 40 & 45\end{array}$

Response of INFLAÇÃO to Cholesk

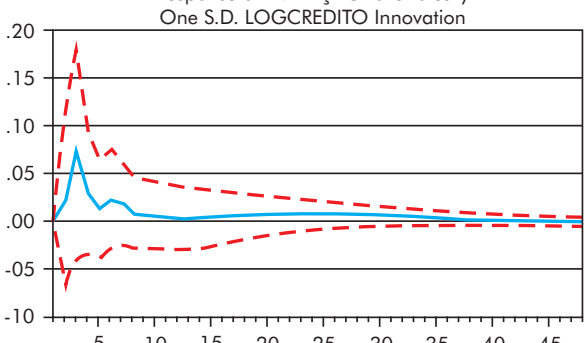

Response of SELIC to Cholesky

One S.D. LOGCREDITO Innovation
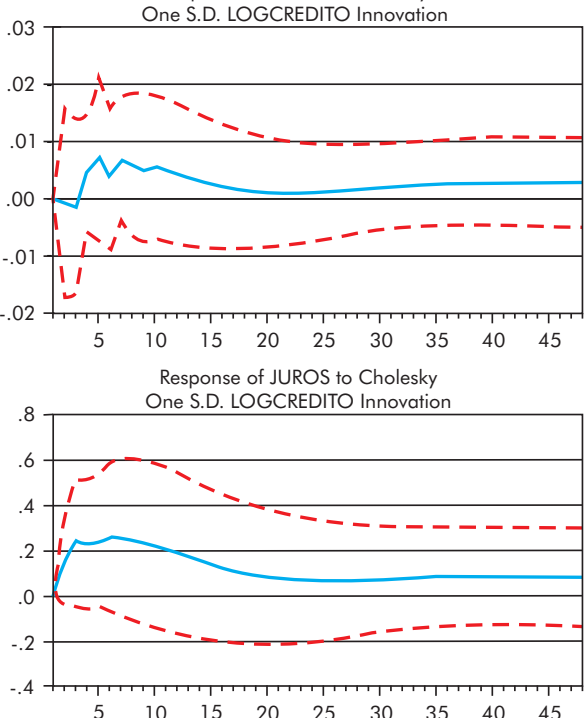

Mod. 1 - Choque no juros

Response of LOGIND to Cholesky

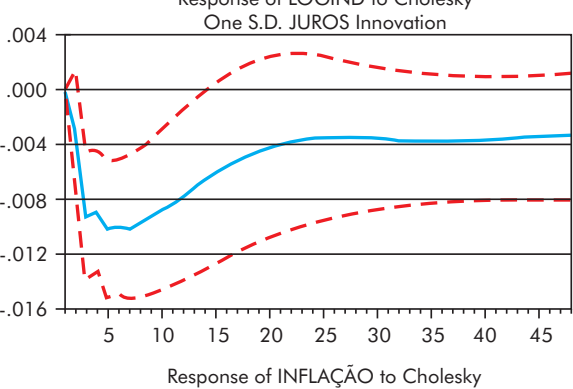

One S.D. JUROS Innovation
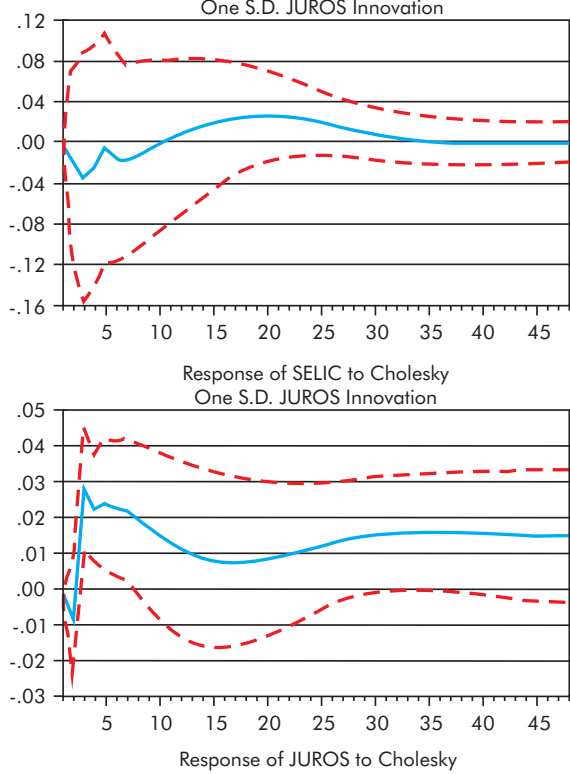
One S.D. JUROS Innovation

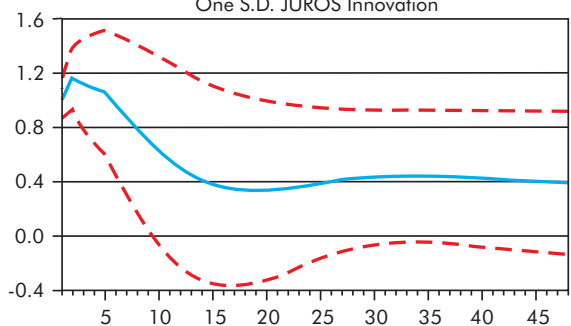


Mod. 1 - Choque no crédito

Response of LOGCREDITO to Cholesky One S.D. LOGCREDITO Innovation

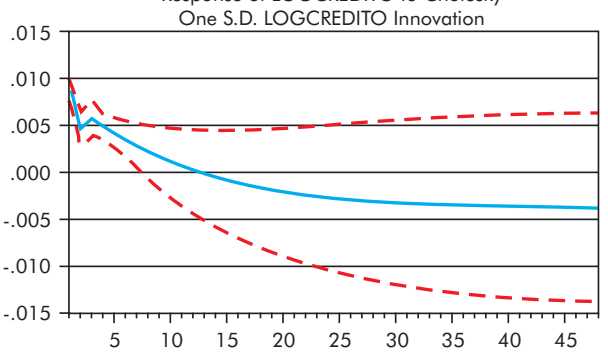

Mod. 1 - Choque no juros

Response of LOGCREDITO to Cholesky One S.D. JUROS Innovation

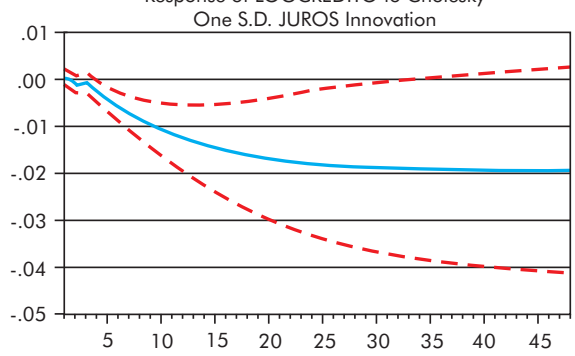

Notas: 1) utilizaram-se três defasagens. O teste HQ indicou duas defasagens, mas para evitar a presença de autocorrelação dos resíduos aumentaram-se as defasagens para até três; 2) as linhas pontilhadas representam um intervalo de confiança de dois desvios padrão.

Fonte: Elaboração própria a partir da saída do software Eviews 8.0.

No que se refere ao choque no volume do crédito, nota-se, que apesar da trajetória de queda a partir do terceiro mês, o crédito permanece acima da linha de base durante 13 meses após um choque positivo sobre ela mesma. O produto aumenta rapidamente nos dois primeiros meses, mas em pequena quantidade ( $0,1 \%$ no segundo mês), no terceiro inicia um processo de retração e só começa a se recuperar a partir do segundo ano após o choque, porém no horizonte de quatro anos não retoma o seu nível inicial. A inflação, por sua vez, eleva-se no terceiro mês (7,3\%), mas após esse período começa a perder força. A procura por empréstimos também gerou taxas elevadas da Selic, refletindo uma política contracíclica do Banco Central. A taxa de juros de mercado seguiu um trajeto semelhante ao da taxa Selic, o que parece refletir uma medida compensadora dos bancos a um aumento dos custos de captação gerada pelo aumento dessa taxa.

No que se refere a um choque na taxa de juros, o volume do crédito apresenta certa resistência à queda até o terceiro mês, após esse período inicia um período de queda e só começa a se estabilizar após dois anos do choque abaixo de -1\%. A resistência nos meses iniciais que seguem ao choque pode estar associada aos contratos dos empréstimos que dificultam uma subsequente mudança no nível de empréstimos. Contudo, na medida em que os contratos vão vencendo, estes não são renovados.

Ainda com relação à inovação na taxa de juros, a produção caiu imediatamente após o choque, e, além de registrar quedas mais intensas que as reduções provocadas pelo choque no volume de empréstimos, configuraram-se em retrações mais persistentes. O nível mais baixo que a produção atingiu após um choque na taxa de juros foi - $1 \%$ no sétimo mês, e após dois anos se estabiliza em um nível em torno de $-0,3 \%$, enquanto a maior retração do produto provocada por um choque no volume de crédito foi de apenas $-0,4 \%$, aproximadamente, e, após dois anos se estabiliza em torno de 
$-0,1 \%$. A inflação apresentou queda de $-3 \%$ e $-2 \%$ no terceiro e no sétimo mês, respectivamente, e, em seguida, inicia uma trajetória ao seu nível inicial. A resposta da Selic parece refletir uma política compensadora do Banco Central ao aumento da taxa de juros de mercado.

As funções impulso-resposta da Figura 2 confirmam claramente a hipótese de Walsh e Wilcox, pois choques na oferta de crédito (choques na taxa de juros de mercado) apresentam efeitos muito mais intensos e persistentes sobre a economia em comparação com choques na demanda por crédito. Sendo assim, choques na quantidade de empréstimos parecem efetivamente medir os choques sobre a demanda de empréstimos, e choques na taxa de juros do mercado são consistentes com as respostas a um choque na oferta de empréstimos.

A fim de obter a importância dos choques de oferta de empréstimos para o produto e para o volume de crédito apresenta-se, na Tabela 3, a decomposição da variância do erro de previsão para essas variáveis e para a taxa de juros de mercado, para um horizonte de 48 meses.

O painel (a) reporta a decomposição da variância do erro de previsão do produto, em que se verifica que, a proporção atribuível aos choques da taxa de juro de mercado chega a ser de seis a 13 vezes maior que a contribuição do volume de empréstimos, o que confirma a hipótese de que a demanda por empréstimos apresenta pouco efeito sobre o produto comparativamente a choques na oferta de crédito. Chama a atenção também o crescimento da contribuição da inflação no produto, que apresentou um crescimento contínuo ao longo do período, ao final dos 48 meses registrou uma contribuição de $35 \%$, o que vai de encontro com a ideia de que um rápido crescimento econômico gera inflação. Dado que esse último apontamento não é objeto de estudo dessa pesquisa, não se aprofunda esse tema.

O painel (b) refere-se à decomposição da variância do erro de previsão do crédito. Neste é possível constatar que choques na taxa de juros de mercado contribuem com $28 \%$, em 12 meses, e com 29\%, em 48 meses, enquanto choques na própria variável contribuem com apenas $8 \%$ e $1 \%$, para esses mesmos períodos, respectivamente. Esses resultados confirmam a hipótese de que o volume de empréstimos é muito mais sensível a choques na oferta de crédito que a choques na demanda de crédito. Destaca-se a contribuição do produto no volume de crédito, confirmando a hipótese de que choques na demanda por crédito advêm de variações do produto. Esse resultado vai de encontro ao estudo de Mendonça e Sachsida (2013), que apontam evidências de que a demanda de crédito no Brasil revelou-se pró-cíclica para um período (junho de 2000 a agosto de 2012) semelhante ao desta pesquisa. 
Tabela 3 - Decomposição da variância para: LOGIND, LOGCREDITO e JUROS

\begin{tabular}{|c|c|c|c|c|c|c|}
\hline \multicolumn{7}{|c|}{ A. LOGIND } \\
\hline Período & Desvio Padrão & LOGIND & INFLACAO & SELIC & JUROS & LOGCREDITO \\
\hline 3 & 0.029688 & 78.96151 & 0.474783 & 8.279235 & 10.59495 & 1.689516 \\
\hline 6 & 0.038089 & 58.89395 & 1.291451 & 11.72823 & 25.95064 & 2.135727 \\
\hline 12 & 0.050784 & 35.18111 & 16.91218 & 11.36956 & 33.75504 & 2.782114 \\
\hline 18 & 0.059288 & 27.10981 & 30.08442 & 9.191841 & 30.86452 & 2.749406 \\
\hline 24 & 0.063475 & 25.96763 & 33.91861 & 8.205493 & 29.27241 & 2.635854 \\
\hline 30 & 0.065804 & 26.41285 & 34.27174 & 7.819406 & 28.94718 & 2.54883 \\
\hline 36 & 0.06764 & 26.5168 & 34.23868 & 7.658695 & 29.10286 & 2.48296 \\
\hline 42 & 0.069385 & 26.24048 & 34.52767 & 7.540608 & 29.26467 & 2.426562 \\
\hline 48 & 0.071056 & 25.90476 & 35.01374 & 7.409264 & 29.29854 & 2.373703 \\
\hline \multicolumn{7}{|c|}{ B. LOGCREDITO } \\
\hline Período & Desvio Padrão & LOGIND & INFLACAO & SELIC & JUROS & LOGCREDITO \\
\hline 3 & 0.108085 & 5.114761 & 2.138889 & 7.56788 & 1.507039 & 83.67143 \\
\hline 6 & 0.145726 & 16.42957 & 16.24956 & 11.07144 & 13.74234 & 42.50709 \\
\hline 12 & 0.198587 & 20.72447 & 32.89728 & 9.834449 & 28.04536 & 8.498439 \\
\hline 18 & 0.218235 & 19.36616 & 39.50331 & 7.988022 & 29.96815 & 3.174364 \\
\hline 24 & 0.22668 & 19.08582 & 42.40695 & 6.829699 & 29.75723 & 1.920308 \\
\hline 30 & 0.234258 & 19.43118 & 43.40834 & 6.165616 & 29.48724 & 1.507629 \\
\hline 36 & 0.243174 & 19.84404 & 43.6242 & 5.789722 & 29.40337 & 1.338667 \\
\hline 42 & 0.252937 & 20.12637 & 43.63621 & 5.564054 & 29.4139 & 1.259463 \\
\hline 48 & 0.26229 & 20.29087 & 43.64101 & 5.412791 & 29.43679 & 1.218547 \\
\hline \multicolumn{7}{|c|}{ C. JUROS } \\
\hline Período & Desvio Padrão & LOGIND & INFLACAO & SELIC & JUROS & LOGCREDITO \\
\hline 3 & 0.743014 & 4.330703 & 10.30413 & 10.65121 & 73.17749 & 1.53646 \\
\hline 6 & 0.816025 & 3.272524 & 32.2329 & 8.179267 & 54.32016 & 1.995142 \\
\hline 12 & 0.859359 & 1.833968 & 56.76026 & 4.74082 & 34.70108 & 1.963878 \\
\hline 18 & 0.874947 & 4.286191 & 60.40036 & 3.794154 & 29.70347 & 1.81583 \\
\hline 24 & 0.878446 & 7.798461 & 58.13771 & 3.586098 & 28.75587 & 1.721862 \\
\hline 30 & 0.881147 & 9.754339 & 55.79838 & 3.710323 & 29.07014 & 1.666811 \\
\hline 36 & 0.882251 & 10.55498 & 54.45132 & 3.886378 & 29.47265 & 1.634673 \\
\hline 42 & 0.882414 & 11.04602 & 53.84155 & 3.964459 & 29.54085 & 1.607121 \\
\hline 48 & 0.882458 & 11.58012 & 53.38878 & 3.987118 & 29.46493 & 1.579057 \\
\hline
\end{tabular}

Fonte: Elaboração própria a partir da saída do software Eviews 8.0.

No painel (c), em que se observa a decomposição da variância da taxa de juro de mercado, chama a atenção o aumento da participação da inflação para a decomposição da variância ao longo dos quatro anos. Esse resultado confirma a ideia de que uma varia- 
ção negativa da inflação promove uma redução da taxa da Selic, que, por sua vez, irá refletir na redução da taxa de juros de mercado, o que se consubstancia num aumento da oferta de crédito. Em contrapartida, a contribuição da Selic para as variações da taxa de juros de mercado foi modesta. Isso pode ser explicado pela influência que essa taxa sofre de outras prováveis variáveis ${ }^{12}$, que não foram incluídas no modelo, como: (i) o Certificado de Depósito Bancário (CDB), que se configura em um título que os bancos emitem para se financiar, refletindo um custo de captação; (ii) o risco de inadimplência, que naturalmente deve aumentar a taxa de financiamento, dentre outras.

\subsection{CHOQUE DA OFERTA DE CRÉDITO PARA PESSOAS FÍSICAS E PESSOAS JURÍDICAS}

Na presente subseção amplia-se a análise para o mercado de crédito para pessoa física e para pessoa jurídica, pois acredita-se ser esta uma questão importante para a compreensão do mecanismo do canal do crédito.

Para isso são realizados dois modelos VAR padrão com as mesmas ordens de inclusão das variáveis que foram utilizadas no modelo geral (Modelo 1), sendo que no modelo para pessoas físicas (Modelo 2) as variáveis de crédito e de juros utilizadas foram específicas para esse mercado. De forma análoga seguiu-se o mesmo método para o mercado de pessoas jurídicas (Modelo 3) ${ }^{13}$. A Figura 3 ilustra as respostas do produto e do volume real de crédito a um choque na taxa de juro para pessoa física (lado esquerdo) e para pessoa jurídica (lado direito).

A Figura 3 revela que o mercado de crédito para pessoa física é muito mais sensível a um choque na oferta de crédito do que o mercado de crédito para pessoa jurídica, visto que a redução do produto e do crédito provocada por um choque na taxa média de juros para pessoas físicas mostrou-se muito mais intensa e persistente do que a retração dessas variáveis induzidas por um choque na taxa média de juros para pessoa jurídica. Ademais, no primeiro mercado, embora as variáveis apresentem certa recuperação, não indicam previsão de retorno ao seu nível inicial. Em contrapartida, no mercado de crédito para pessoa jurídica, as variáveis não só voltaram ao nível que precede o choque, como também ultrapassaram esse nível.

12 Ver Mendonça e Sachsida (2013).

${ }^{13}$ Contudo, diferentemente do que foi apresentado para o Modelo 1, na análise impulso-resposta dos Modelos 2 e 3 mostram-se os resultados apenas para o produto (LOGIND) e para o volume de crédito real (LOGCRÉDITO_PF e LOGCRÉDITO_PJ). 


\section{Figura 3 - Funções de resposta a impulso na taxa média de juros (logcrédito_pf e logcrédito_pj)}
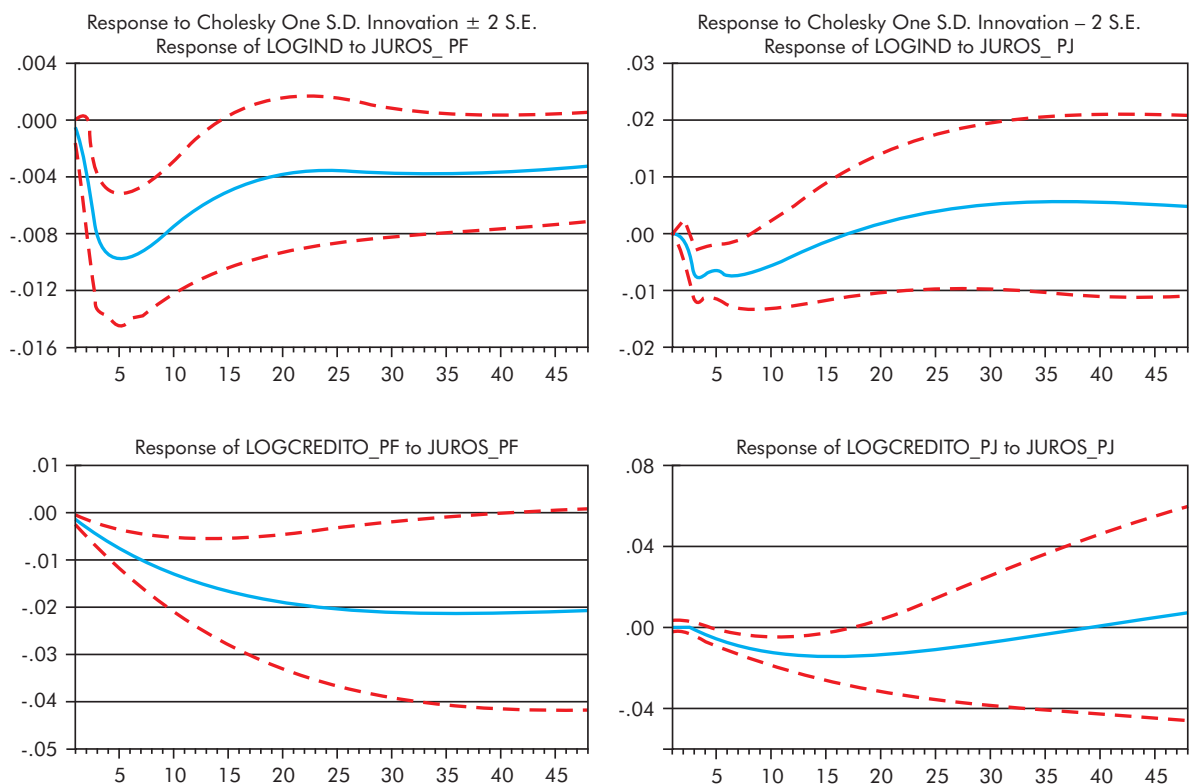

Notas: 1) no Modelo 2 utilizaram-se três defasagens (os testes SC e HQ indicaram uma defasagem, mas como não é possível estimar com uma defasagem foram aumentadas as defasagens até três, sem indicar presença de autocorrelação); 2) no Modelo 3 utilizaram-se três defasagens (indicadas pelos testes FPE e HQ); 3) as linhas pontilhadas representam um intervalo de confiança de dois desvios padrão.

Fonte: Elaboração própria a partir da saída do software Eviews 8.0

A menor sensibilidade do crédito para as empresas em relação ao crédito para as famílias pode ser explicada pelo fato de que as empresas podem dispor de outras fontes de recursos, como empréstimos externos. Ressalva-se que as pequenas e microempresas, que no Brasil são um número substancialmente grande ${ }^{14}$, por apresentarem restrições financeiras, têm acesso limitado ao mercado financeiro. Já a maior sensibilidade do crédito para pessoas físicas está relacionada à assimetria de informação que acomete esse mercado de forma muito mais vigorosa do que o mercado de crédito para pessoa jurídica. Isso ocorre porque empréstimos às pessoas físicas são, em grande medida, contratados sem garantia, logo, nesse segmento de mercado o risco de inadimplência é significativamente maior, o que faz com que a taxa de juros para esse mercado seja mais elevada.

${ }^{14}$ Segundo o SEBRAE (2015), no Brasil existem 6,4 milhões de estabelecimentos. Desse total, 99\% são micro e pequenas empresas (MPE). 
Além de todos os fatores que acometem o mercado de crédito para pessoas físicas, a maior sensibilidade do produto a um choque na taxa de juros desse mercado também é reflexo do maior volume do crédito para o mesmo no período estudado, fazendo com que uma redução da oferta de crédito para pessoas físicas, como aconteceu no período pós-crise de 2008, interfira de forma mais intensa no produto.

\section{CONCLUSÕES}

Diversos trabalhos utilizam choques na Selic para inferir variações sobre a oferta de crédito, contudo essas pesquisas estão suscetíveis ao problema de endogeneidade, uma vez que o nível de empréstimos pode ser afetado tanto pela demanda quanto pela oferta de crédito. Desse modo, essa dificuldade pode acarretar em uma identificação inadequada de choques de oferta de empréstimos, pois o que pode estar sendo identificado é apenas uma redução da demanda por crédito, assim, o que estaria em funcionamento seria somente o canal da taxa de juros, e não o canal do crédito. Ao adotar choques na taxa de juros de mercado para identificar mudanças na oferta de crédito nesta pesquisa, estratégia proposta por Walsh e Wilcox (1995), contornou-se o problema de identificação da oferta de empréstimos, pois, no caso de uma política monetária restritiva, os bancos aumentam a sua taxa de juros para compensar a perda de rentabilidade causada pela redução da diferença coma taxa de juros da política monetária, o que configura uma redução da oferta de crédito.

Os resultados obtidos por meio do Modelo 1, que se mostraram consistentes com a hipótese de que um choque positivo na taxa de juros reflete uma redução na oferta de crédito, foram as quedas abruptas do produto e do volume real de empréstimos. Tais movimentos foram tão intensos que ambos não retomaram o seu nível de crescimento inicial. A retração do produto, especificamente, pode refletir a forte dependência que os agentes econômicos, as famílias e as empresas têm em relação ao crédito. Já os resultados que estão em concordância com a acepção de que um choque positivo no volume de crédito se mostra eficaz em captar uma ampliação na demanda por crédito em momentos de crescimento econômico foram os aumentos pouco expressivos do produto e do volume real de crédito, visto que o esperado era que, ao contrário de choques na oferta de crédito, choques na demanda de empréstimos não exercessem efeitos expressivos sobre a economia real. Em suma, observou-se que o choque na oferta de crédito impactou de forma muito mais acentuada o lado real da economia do que o choque na demanda de crédito, o que está de acordo com as predições teóricas do canal do crédito.

Essa separação entre os choques foi possível por meio da ordenação de Cholesky, a qual mostrou-se uma ferramenta adequada para identificar a demanda e a oferta de 
crédito. Por meio dessa ordenação, discutida na seção 4, faz-se uma observação interessante: um choque na demanda de crédito, além de não afetar contemporaneamente o produto, a inflação e a Selic, não irá afetar contemporaneamente a oferta de crédito. Por outro lado, um choque na oferta de crédito, embora não afete contemporaneamente o produto, a inflação e a Selic, irá afetar contemporaneamente a demanda por crédito. Resumindo, a demanda de crédito não afeta contemporaneamente a oferta de crédito, mas a oferta de crédito afeta contemporaneamente a demanda de crédito.

Outro sinal de existência do canal do crédito é detectado quando se analisam os efeitos de choques na oferta de crédito separadamente para o mercado de crédito para pessoa física e para pessoa jurídica. Nesta análise confirmam-se os pressupostos desse canal de que mercados que são supostamente mais acometidos pela assimetria de informação, como é o caso do mercado de crédito para pessoa física, respondem de forma mais rápida e mais intensa diante de um choque de oferta de crédito. Desse modo, o produto é mais sensível à política monetária nesse mercado.

As evidências da existência do canal do crédito para o Brasil implicam que as autoridades monetárias deveriam dar maior atenção ao nível da taxa de juros de mercado, principalmente no que se refere ao nível dessa variável para a pessoa física, pois o efeito da política monetária sobre esta potencializa os resultados sobre o nível de atividade econômica. Esse resultado vai de encontro com o de Oreiro e Araújo (2011). Segundo esses autores, o BCB cometeu uma série de erros na condução da política monetária no último trimestre de 2008 por desconsiderar o canal do crédito nos modelos de previsão. Dessa forma, a conclusão do estudo foi que a autoridade monetária subestimou os impactos da crise econômica mundial sobre o nível de atividade produtiva e, se houvesse uma inserção do canal do crédito na atuação do BCB para a análise monetária naquele ano, o Brasil sairia mais rápido da crise, pois o BCB teria iniciado o ciclo de redução da taxa básica logo após o estouro da crise.

\section{REFERÊNCIAS}

ABRITA, M. B. et al. O Crédito como Mecanismo de Transmissão da Política Monetária: Aspectos Teóricos e Evidências Empíricas para o Brasil. Nova Economia, v. 24, n. 2, p. 225 $242,2014$.

AKERLOF, G. A. The Market for "Lemons": Quality Uncertainty and the Market Mechanism. Quaterly Jounal of Economics, v. 84, n. 3, p. 488-500, 1970.

ARAÚJO, F. A. Instituições bancárias e transmissão de política monetária: um estudo microeconômico aplicado ao Brasil. Dissertação (Mestrado em Economia) - Centro de Desenvolvimento e Planejamento Regional, Faculdade de Ciências Econômicas, Universidade Federal de Minas Gerais, Belo Horizonte, 2012. 
BANCO CENTRAL DO BRASIL (BCB). SGS - Sistema Gerenciador de Séries Temporais - v. 2.1 (módulo público). [On-line] BCB, vários anos. Disponível em: <https://www3.bcb.gov.br/ sgspub/localizarseries/localizarSeries.do?method=prepararTelaLocalizarSerie. Acesso em: 03 set. 2015.

BERNANKE, B. S.; GERTLER, M. Inside the Black Box: The Credit Channel of Monetary Policy Transmission. Journal of Economic Perspectives, v. 9, n. 4, p. 27-48, 1995.

BERNANKE, B. S; BLINDER, A. S. Credit, money, and aggregate demand. American Economic Review, v. 78, n. 2, p. 435-39, 1988.

BEZERRA, J. F.; SILVA, I. E. M.; LIMA, R. C. Estudo Empírico da Operacionalidade do Canal de Crédito Bancário no Nordeste e no Brasil. Revista Econômica do Nordeste, v. 44, n. 4, p. 957-974, 2013.

CARNEIRO, D. D; SALLES, F. M; WU, T. Y. H. Juros, câmbio e as imperfeições do canal de crédito. Economia Aplicada, v. 10, n. 1, p. 7-23, 2006.

CAVALCANTI, M. A. F. H. Identificação de modelos VAR e causalidade de Granger: uma nota de advertência. Economia Aplicada, v. 14, n. 2, p. 251-260, 2010.

DENARDIN, A. A. Assimetria de informação, intermediação financeira e o mecanismo de transmissão da política monetária: evidências teóricas e empíricas para o canal do empréstimo bancário no Brasil (1995-2006). Tese (Doutorado em Economia) - Programa de Pós-Graduação em Economia, Universidade Federal do Rio Grande do Sul, Porto Alegre, 2007.

DENARDIN, A. A; BALBINOTTO NETO, G. O mecanismo de transmissão da política monetária: evidências empíricas para o canal do empréstimo bancário no Brasil. In: ENCONTRO DE ECONOMIA DA REGIÃO SUL - ANPEC/SUL, 17, Maringá, Paraná, 6-8 ago. 2014.

DIAS JUNIOR, P. H. D.; DENARDIN, A. A. Mecanismo de transmissão de política monetária via canal do balanço patrimonial para o período Pós-Plano Real. In: ENCONTRO REGIONAL DE ECONOMIA - ANPEC SUL, Porto Alegre, Rio Grande do Sul, 11-13 ago. 2010.

FONSECA, M. W. Mecanismo de transmissão da política monetária no Brasil: uma análise pósregime de metas de inflação. Tese (Doutorado em Economia) - Programa de Pós-Graduação em Desenvolvimento Econômico, Universidade Federal do Paraná, Curitiba, Paraná, 2008.

FREIXAS, X.; ROCHET, J.C. Microeconomics of Banking. Cambridge, MA: MIT Press, 1997.

FUINHAS, J. A. O canal de crédito e a política monetária. Texto para Discussão, Departamento de Gestão e Economia, Universidade da Beira Interior, n. 4, 2002.

GRAMINHO, F. M. O canal de empréstimos bancários no Brasil: uma evidencia microeconômica. Dissertação (Mestrado em Economia) - Escola de Pós-Graduação em Economia, Fundação Getulio Vargas, Rio de Janeiro, 2002.

HICKS, J. R. Mr. Keynes and the "Classics": A suggested interpretation. Econometrica, v. 5, n. 2, p. 147-159, 1937.

INSTITUTO DE PESQUISA ECONÔMICA E APLICADA (IPEA). IPEADATA. [On-line] IPEA, vários anos. Disponível em:<http://www.ipeadata.gov.br/>. Acesso: 09 set. 2015.

KASHYAP, A. K.; STEIN. J. C. Monetary policy and bank lending. Monetary Policy, 1993.

KASHYAP, A. K.; STEIN. J. C. The impact of monetary policy on bank balance sheets. CarnegieRochester Conference Series on Public Policy, v. 42, p. 151-95, 1994. 
MELTZER, A. H. Monetary, credit and (other) transmission processes: a monetarist perspective. Journal of Economic Perspectives, v. 9, n. 4, p. 49-72, 1995.

MENDONÇA, M. J.; SACHSIDA, A. Identificando a demanda e a oferta de crédito bancário no Brasil. Texto para Discussão, IPEA, n. 1837, 2013.

MISHKIN, F. S. Symposium on the monetary transmission mechanism. The Journal of Economic Perspectives, v. 9, n. 4, 1995.

OBSTFELD, M.; ROGOFF, K. The mirage of fixed exchange rates. The Journal of Economic Perspectives, v. 9, n. 4, 1995.

OREIRO, J. L.; ARAÚJO, E. C. “A crise de 2008 e os erros do Banco Central”. In: BRESSER-PEREIRA, L. C. (Org.). Depois da crise: A China no centro do mundo? Rio de Janeiro: Editora FGV, 2011.

PACHECO, L. M. M. D. O mecanismo de transmissão da política monetária o papel dos preços dos activos. Tese (Doutorado em Economia) - Instituto Superior de Economia e Gestão, Lisboa, Portugal, 2006.

PEEK, J.; ROSENGREN, E. S. Bank regulation and the credit crunch. Journal of Banking \& Finance, v. 19, n 3-4, p. 679-692, 1995.

PEEK, J.; ROSENGREN, E. S. The role of banks in the transmission of monetary policy. Boston, MA: Federal Reserve Bank of Boston, 2013.

SEBRAE - SERVIÇO BRASILEIRO DE APOIO ÀS MICRO E PEQUENAS. Disponível em: $<$ http://www.sebraesp.com.br/index.php/234-uncategorised/institucional/pesquisas-sobre-micro-e-pequenas-empresas-paulistas/micro-e-pequenas-empresas-em-numeros $>$. Acesso em: 04 set. 2015.

SHARPE, S. A. Asymmetric information, bank lending and implicit contracts: a stylized model of customer relationships. Journal of Finance, v. 45, n. 4, p. 1069-87, 1990.

SIMS, C. A.; STOCK, J. H.; WATSON, M. W. Inference in Linear time series models with some unit roots. Econometrica, v. 58, n. 1, p. 113-144, 1990.

SOUZA SOBRINHO, N. F. Uma avaliação do canal de crédito no Brasil. Dissertação (Mestrado de Economia) - Faculdade de Economia, Administração e Contabilidade, Universidade de São Paulo, São Paulo, 2003.

TAKEDA, T.; ROCHA, F.; NAKANE, M. I. The reaction of bank lending to monetary policy in Brazil. Revista Brasileira de Economia, v. 59, n. 1, p. 107-126, 2005.

TAYLOR, J. B. The monetary transmission mechanism: an empirical framework. The Journal of Economic Perspectives, v. 9, n. 4, p. 11-26, 1995.

WALSH, C. E. Monetary theory and policy. Cambridge, MA: The MIT Press, 1988.

WALSH, C. E.; WILCOX, J. A. Bank credit and economic activity. Conference Series: Proceedings, Federal Reserve Bank of Boston, p. 83-125, 1995. 